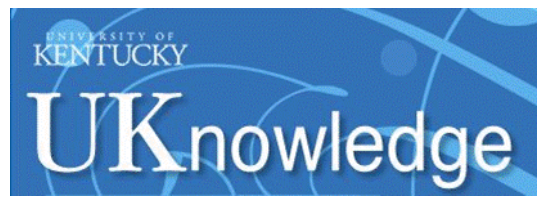

University of Kentucky

UKnowledge

Molecular and Cellular Biochemistry Faculty

Publications

Molecular and Cellular Biochemistry

$11-4-2017$

\title{
Deficiency of KLF4 Compromises the Lung Function in an Acute Mouse Model of Allergic Asthma
}

\author{
Jeanette A. Nimpong \\ Benedict College \\ Wintana Gebregziabher \\ Benedict College \\ Udai P. Singh \\ University of South Carolina \\ Prakash Nagarkatti \\ University of South Carolina \\ Mitzi Nagarkatti \\ University of South Carolina
}

Elllow this and additionahworks,at:https://uknowledge.uky.edu/biochem_facpub

Part of the Allergy and Immunology Commons, Biochemistry, Biophysics, and Structural Biology Commons, and the Cell and Developmental Biology Commons

Right click to open a feedback form in a new tab to let us know how this document benefits you.

\section{Repository Citation}

Nimpong, Jeanette A.; Gebregziabher, Wintana; Singh, Udai P.; Nagarkatti, Prakash; Nagarkatti, Mitzi; Hodge, Johnie; Liu, Chunming; Fan, Daping; and Ai, Walden, "Deficiency of KLF4 Compromises the Lung Function in an Acute Mouse Model of Allergic Asthma" (2017). Molecular and Cellular Biochemistry Faculty Publications. 155.

https://uknowledge.uky.edu/biochem_facpub/155

This Article is brought to you for free and open access by the Molecular and Cellular Biochemistry at UKnowledge. It has been accepted for inclusion in Molecular and Cellular Biochemistry Faculty Publications by an authorized administrator of UKnowledge. For more information, please contact UKnowledge@lsv.uky.edu. 


\section{Deficiency of KLF4 Compromises the Lung Function in an Acute Mouse Model of}

Allergic Asthma

\section{Digital Object Identifier (DOI)}

https://doi.org/10.1016/j.bbrc.2017.08.146

\section{Notes/Citation Information}

Published in Biochemical and Biophysical Research Communications, v. 493, issue 1, p. 598-603.

(c) 2017 Elsevier Inc. All rights reserved.

This manuscript version is made available under the CC-BY-NC-ND 4.0 license

https://creativecommons.org/licenses/by-nc-nd/4.0/.

The document available for download is the author's post-peer-review final draft of the article.

Authors

Jeanette A. Nimpong, Wintana Gebregziabher, Udai P. Singh, Prakash Nagarkatti, Mitzi Nagarkatti, Johnie Hodge, Chunming Liu, Daping Fan, and Walden Ai 


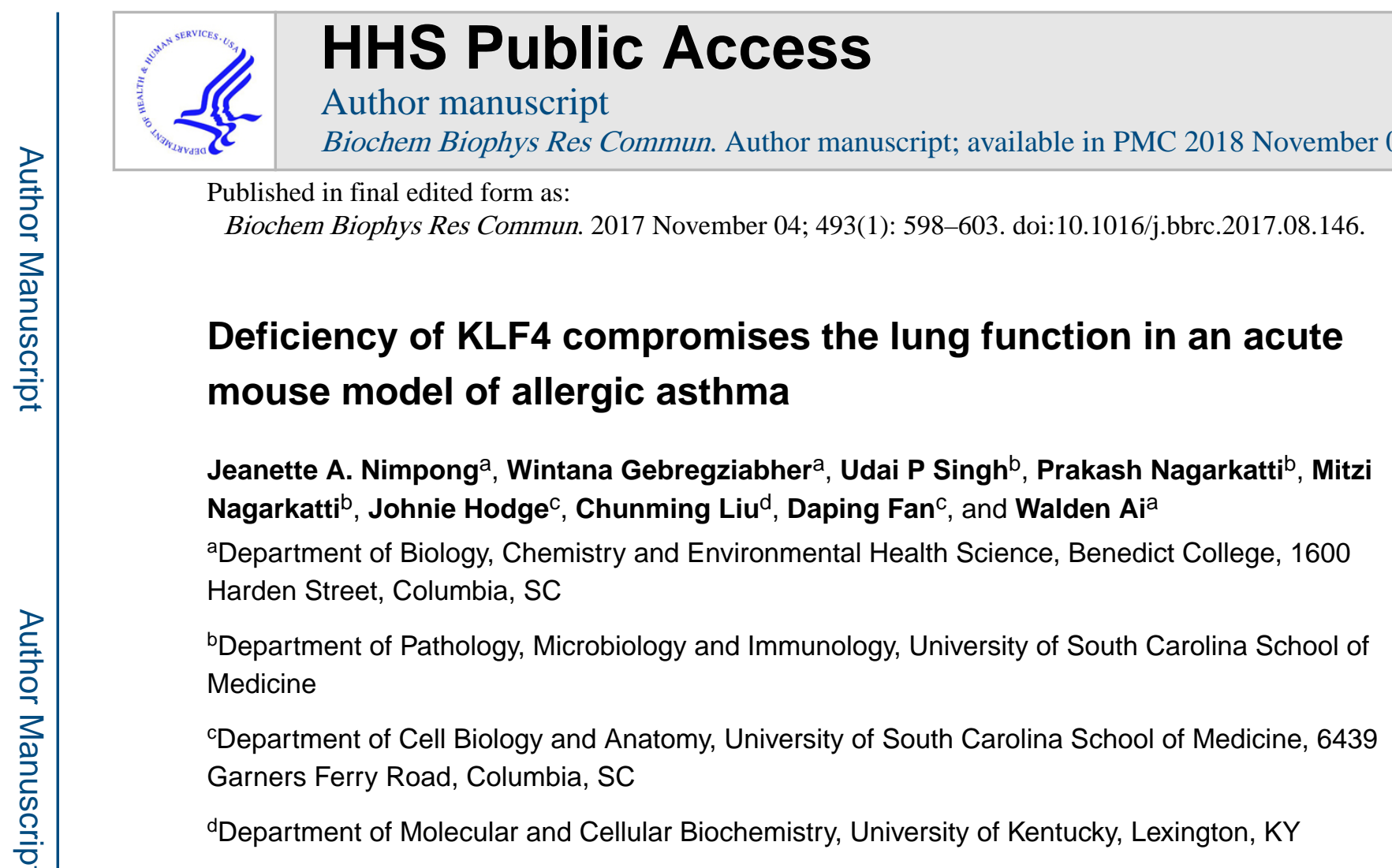

\begin{abstract}
Asthma is a chronic inflammatory disease of the airways and the mechanisms are not fully understood. Myeloid-derived suppressor cells (MDSCs) are a heterogeneous group of monocytes, granulocyte and myeloid cells at early stage of differentiation. They possess phenotypic plasticity and regulate airway inflammation. We recently reported that Kruppel-like factor 4 (KLF4) regulates MDSC differentiation into fibrocytes, emerging effectors in chronic inflammation. However, the role of KLF4 in asthma is not known. Thymic stromal lymphopoietin (TSLP) is an epithelial cell-derived cytokine and a key initiator of allergic airway inflammation. Given the fact that TSLP promotes Th2 cytokine production that increases MDSC differentiation into fibrocytes, we postulate that KLF4 regulates asthma in a TSLP-dependent manner. In this study, we utilized a model of allergic asthma with ovalbumin challenge (OVA). We found that upon OVA treatment the wild type mice had increased MDSC infiltration into the lung, up-regulation of KLF4 and TSLP gene expression, and higher levels of Th2 cytokines including IL4 and IL13. Consistently, lack of KLF4 expression in monocytes and lung epithelial cells resulted in decreased TSLP expression and lower levels of Th2 cytokines in mice, and fibrocyte generation was compromised. KLF4 deficiency in these cells also led to decreased airway hyperresponsiveness (AHR), a cardinal feature of asthma, as assessed by whole body plethysmography. Moreover, lung fibrosis as measured by trichome staining was attenuated and the population of CD45+COL1A1+ fibrocytes was diminished in this setting. Together, our results suggest that KLF4 regulates asthma development in a TSLP- and fibrocyte-dependent manner.
\end{abstract}

Corresponding author: Dr. Walden Ai, Department of Biology, Chemistry and Environmental Health Science, Benedict College, 1600 harden street, Columbia, SC 29204, walden.ai@ benedict.edu.

Publisher's Disclaimer: This is a PDF file of an unedited manuscript that has been accepted for publication. As a service to our customers we are providing this early version of the manuscript. The manuscript will undergo copyediting, typesetting, and review of the resulting proof before it is published in its final citable form. Please note that during the production process errors may be discovered which could affect the content, and all legal disclaimers that apply to the journal pertain. 


\section{Keywords}

KLF4; Asthma; Myeloid-derived suppressor cells (MDSCs); fibrocytes; thymic stromal lymphopoietin (TSLP); airway hyperresponsiveness (AHR)

\section{Introduction}

Asthma is a heterogeneous inflammatory disease of the airways [1] affecting more than 22 million people in the US [2]. It is characterized by airway remodeling, a structural dysfunction potentially affected by epithelial-mesenchymal transition (EMT) and modified by type 2 inflammation [3,4]. Optimal control of asthma requires inhibition of both the inflammatory and structural components of the asthma response.

Myeloid-derived suppressor cells (MDSCs) are a heterogeneous group of monocytes that possess phenotypic plasticity [5]. They are master regulators of the airway inflammation which precedes asthma [6]. However, how MDSCs regulate asthma remains largely unknown [7]. Recently, MDSCs showed a high potential to differentiate into fibrocytes in response to Th2 cytokines [8]. It is now understood that fibrocytes are emerging effectors in chronic inflammation [9] and are precursors of myofibroblasts critical to airway remodeling in asthma [10]. Therefore, the presence of fibrocytes in chronic asthmatic lungs [11] suggests that MDSCs not only execute their immune function to regulate airway inflammation in the early stage of asthma, but also promote airway remodeling after they adopt a fibrocyte fate. However, whether fibrocyte generation from MDSCs is modulated by airway epithelial cells, and contributes to EMT, is not clear.

Thymic stromal lymphopoietin (TSLP) is an epithelial-cell-derived cytokine and a key initiator of allergic airway inflammation [12]. It regulates many types of cells, including Th2 cells in asthma. In a recent phase II clinical trial, a human anti-TSLP monoclonal antibody reduced allergen-induced bronchoconstriction and indexes of airway inflammation [13]. These results indicated a pivotal role of TSLP in allergen-induced airway responses in patients with allergic asthma. However, this antibody led to significant adverse events. Thus, there is an urgent need to study the precise function of TSLP in asthma before developing TSLP-specific interventions in patients. The fact that TSLP promotes the production of Th2 cytokines [14], which is critical to fibrocyte generation [15] suggests that TSLP may induce the asthmatic response in a fibrocyte-dependent manner.

We recently reported that fibrocyte generation from MDSCs was regulated by KLF4 [16,17], a transcription factor cloned in epithelial cells. KLF4 is also expressed in hematopoietic cells and critical to inflammation [18] and monocyte differentiation [19]. The role of KLF4 in asthma pathogenesis has not been explored. In the current study, we tested our hypothesis that KLF4 in monocytes and epithelial cells promotes the asthmatic response by affecting TSLP-dependent fibrocyte generation from MDSCs in the airway. 


\section{Materials and methods}

\subsection{A Mouse model of allergic asthma}

Six to eight weeks old female BALB/c mice, weighing $20 \pm 2 \mathrm{~g}$, were purchased from Jackson Laboratory (Bar Harbor, ME, USA). All mice were housed under specific pathogenand ovalbumin (OVA)-free conditions. All experimental mice used in this study were kept under a protocol approved by the Institutional Animal Care and Use Committee at University of South Carolina School of Medicine. Mice were evenly divided into two groups and challenged either with PBS or OVA. Specifically, they were sensitized on Days 0 and 7 by an intraperitoneal injection of a mixture containing $50 \mu \mathrm{g}$ of ovalbumin (OVA; Grade V, Sigma) and $1 \mathrm{mg}$ of $\mathrm{Al}(\mathrm{OH})_{3}$ (Alum) in PBS (a total volume of $0.2 \mathrm{ml}$ ). On Day 14, mice were challenged intranasally (i.n.) with $40 \mu \mathrm{L}$ of $0.03 \%$ OVA in PBS (OVA) or PBS alone (PBS). The mice were sacrificed on day 17 for various analyses (Fig 1A). The control animals received two immunizations with OVA/Alum and six challenges with PBS. In addition, KLF4 deficient mice were used in the study. These mice were generated by crossing fibroblast specific protein 1 promoter (FSP-1)-Cre transgenic mice on BalB/c background (Jackson) with our KLF4(flox) mice form our laboratory.

\subsection{Immunohistochemistry (IHC)}

Serial sections of lung tissues on charged glass slides were rehydrated through xylene and ethanol to water, subjected to antigen retrieval and stained with the KLF4 antibodies as described previously [16]. Goblet hyperplasia was evaluated by Periodic Acid Schiff (PAS) staining [20], and lung fibrosis was assessed by Masson's trichrome staining [21]. Images were captured on an Olympus microscope, model BX51 equipped with a digital camera and Optronics Version 1.2 software. All slides were evaluated by a board certified pathologist, who is blind and independent on this study.

\subsection{Cytokine measurement using bronchoaveolar lavage fluid (BALF)}

BALF was collected as previously described by others [22]. Cytokines present in the BALF were analyzed using a Bio-Plex Pro $^{\text {TM }}$ 23-Plex panel (Bio-Rad) according to the manufacturer protocol. Duplicate samples were analyzed from each animal. Data were represented using Microsoft Excel.

\subsection{Flow Cytometry}

Lung mononuclear cells were isolated and purified after collagenase digestion as described previously [23]. After further purification, the lung mononuclear cells were incubated with different antibodies including CD11b, Ly6G, CD45 (eBioscience), and Col1A1 (Rockland Immunochemicals, Inc) and then analyzed with a BD FACS Aria II flow cytometer.

\subsection{Quantitative RT-PCR}

Lung tissue was collected, frozen in liquid nitrogen, and then stored at $-80^{\circ} \mathrm{C}$. Total RNA was extracted with Trizol Reagent (Invitrogen). cDNAs were synthesized by reverse transcriptase MML-V (Promega) followed by quantitative real-time PCR analysis with specific primers for KLF4, FSP1, CCR2, and TSLP and SYBR Green master mix (Biorad). 
GAPDH was used as a normalization control. Primer sequences were as the following:

mKLF4 (forward: 5' -CCGGCGGGAAGGGAGAAGA-3' ${ }^{\prime}$, reverse: 5' -

GCTAGGAGGGCCGGGTTGTTAC-3'), mFSP1 (forward: 5' -

AGCTGAACAAGACAGAGCTC-3' ${ }^{\prime}$, reverse: 5' -ACAGGAAGACACAGTACTCC-3'), mCCR2 (forward 5' $5^{\prime}$-ATTCTCCACACCCTGTTTCG-3', reverse 5'

ATGCAGCAGTGTGTCATTCC- $3^{\prime}$ : reverse:), mTSLP (forward: $5^{\prime}$ -

CTGAGAGAAATGACGGTACTCAGG-3', reverse: $5^{\prime}$ -

GGAGATTGCATGAAGGAATACCAC-3'), mGAPDH (forward: $5^{\prime}$ -

AGGCCGGTGCTGCTGAGTATGTC-3' ${ }^{\prime}$, reverse: 5' -CAGAAGGGGCGGAGATGAT-3').

\subsection{Airway resistance measurement}

The airway resistance to inhaled methacholine (MCh; Sigma-Aldrich) was measured using the Buxco Finepoint NAM System (TBL4999, Buxco, CT) 48 hours after the last OVA challenge in mice by following the protocol from the manufacturer. It is designed to measure airway mechanics by non-invasive whole body plethysmography. Briefly, after a short acclimation to the chamber, the mice received an initial baseline challenge of saline, followed by increasing doses of nebulized methacholine. During exposure to methacholine, each mouse was given either 0 (saline), 6.25 , or $12.5 \mathrm{mg} / \mathrm{ml}$ of Mch, followed by continuous measurement of specific airway resistance (sRaw) for 3 minutes. The airway responses to the inhaled MCh were recorded by a computer.

\subsection{Statistical Analysis}

For in vivo studies, each group consisted of three mice. In vitro assays were performed in triplicates. Data is represented as mean \pm SEM. Data were analyzed using $t$ test (two-group comparison) or one-way ANOVA (multi-group comparison). A p-value $<0.05$ was considered to indicate statistical significance.

\section{Results}

\subsection{Increased goblet cell hyperplasia was linked with up-regulation of KLF4 in a mouse model of allergic asthma}

The important role of MDSCs in asthma [6,24] and KLF4's regulation of MDSCs from our tumor studies [25] prompted us to hypothesize that KLF4 may be involved in asthma development. To this end, we utilized an acute mouse model of allergic asthma as described in the Materials and Methods (Fig 1A). After ovalbumin challenge, goblet cell hyperplasia in the airway of the mice, a feature of asthma pathogenesis from previous studies, was prominent when compared to that of the control mice (pointed by arrow heads in Fig 1B). Consistent with the requirement of KLF4 in goblet cell development, KLF4 expression was shown to be increased using immunohistochemistry (IHC) in the airway epithelium. As shown in Fig 1C, there were three KLF4-staining positive cells in the epithelium of the control group. This number was significantly increased (32) in the OVA challenged group. 


\subsection{Increased levels of Th2 cytokines were associated with infiltration of more MDSCs and up-regulation of KLF4 and TSLP in allergic asthma}

Levels of Th2 cytokines often increase in the pathogenesis of asthma. Indeed, in our allergic mouse model of asthma, IL4 levels in the bronchoaveolar lavage fluid (BALF) increased from $22 \mathrm{ng} / \mathrm{ml}$ to $45 \mathrm{ng} / \mathrm{ml}$ and IL13 levels increased from 62ng/ml to 92ng/ml (Fig 2A, $p<0.05)$. To examine whether Th2 cytokine induction was associated with MDSC recruitment, we analyzed single cells purified from the lung tissues by flow cytometry using CD11b and Ly6G as markers of MDSCs. As shown in Fig 2B, while the MDSCs are 5.4\% in the control lungs, this number increased to $14.6 \%$ in OVA challenged lung tissues. In addition, we performed qRT-PCR analysis to examine the expression of KLF4 and TSLP, the latter is a key initiator of airway inflammation in allergic asthma. As expected, mRNA levels of both KLF4 and TSLP increased to 2-3 folds upon OVA challenge (Fig 2C).

\subsection{KLF4 ablation in CCR2+MDSCs in mice reduced TSLP expression in the lung and attenuated fibrocyte generation}

We recently reported that KLF4 was highly expressed in CCR2+MDSCs [17]. This, coupled with increased MDSCs upon allergic asthma challenge (Fig 2B), led us to postulate that KLF4 in CCR2+MDSCs may directly regulate the pathogenesis of allergic asthma. To test this possibility, we sought to generate a knockout mouse model in which KLF4 was specifically ablated in CCR2+MDSCs. Due to the highest expression level of FSP-1 being present in CCR2+MDSCs among all MDSC subpopulations ([17] and data not shown), we elected to cross FSP-1-Cre transgenic mice with KLF4 (flox) mice to generate an FSP-1Cre/KLF4 (flox) conditional knockout mouse model. KLF4 knockout in monocytes in FSP-1-Cre/KLF4 (flox) mice (KLF4 ${ }^{-/}$) was demonstrated by qRT-PCR using RNA samples purified from the blood monocytes (Fig 3A). KLF4 deficiency was also linked with significant low expression of FSP-1 and CCR 2 in the blood, and TSLP in the lung. TSLP is mainly expressed in keratinocytes and epithelial cells [14]. Down-regulation of TSLP in $\mathrm{KLF}^{-/-}$mice led us to hypothesize that $\mathrm{KLF}^{-/-}$mice also possessed KLF4 deficiency in these cells. Indeed, IHC showed absence of KLF4 staining in skin keratinocytes (data not shown), and the numbers of KLF4-positive cells decreased by $~ 80 \%$ in the airway epithelium of $\mathrm{KLF}^{-/-}$mice (Fig 3B). To examine the potential immunological defects in $\mathrm{KLF}^{-/-}$mice, we measured the cytokine/chemokine levels in sera. Levels of IL-4 and IL-5 were significantly increased, but levels of IL-12 (P40), a shared subunit of IL-12 and IL-23 [26], were decreased (Fig 3C). The roles of IL-4 and IL-5 in the polarization of Th2 cells [27] and IL-12(P40) in the polarization of Th1 cells [28] suggest that KLF4 ablation in FSP-1-expressing cells promotes Th2 cell polarization. Interestingly, the levels of granulocyte colony-stimulating factor (G-CSF) and macrophage inflammatory protein 1 alpha (MIP-1a) were also significantly increased in KLF4 null mice (Fig 3C). Given the association of G-CSF and MIP MIP-1a with monocytic MDSC generation [29] or migration [30,31], these data suggest that KLF4 in FSP-1-expressing cells regulates the function of CCR2+MDSCs. In agreement with this possibility and consistent with a role of CCR2+MDSCs in fibrocyte generation [17], the number of fibrocytes generated from splenocytes decreased from $112 \pm 8$ (per $10^{5}$ cells) in the WT mice to $46 \pm 4$ (per $10^{5}$ cells) in $\mathrm{KLF}^{-/-}$mice (Fig 3D). 


\subsection{KLF4 deficiency attenuated AHR and fibrosis accompanied by significantly decreased population of pulmonary fibrocytes in an acute mouse model of allergic asthma}

To examine the effect of KLF4 deficiency on allergic asthma, we sensitized six female wild type BalB/c mice (WT) and six female FSP-1-Cre/KLF4 (flox) mice (KLF4 ${ }^{-/}$) at 6-8 weeks old. Mice were evenly divided into two subgroups and challenged either with PBS or OVA as described in Fig 1. Three days later, the mice were loaded into the Buxco Finepoint NAM system (TBL4999) to measure airway mechanics. To obtain a dose response curve, stepwise increasing concentrations of methacholine were administered, followed by continuous measurement of specific airway resistance (sRaw). The OVA challenge increased the sRaw for about $32 \%$ in the WT mice at the dosage of $12.5 \mathrm{mg} / \mathrm{ml} \mathrm{MCh}$. However, while the unchallenged $\mathrm{KLF}^{-/-}$mice had decreased sRaw, the OVA challenge did not increase the sRaw at the same dosage of MCh (Fig 4A). Similarly, the level of Th2 cytokine IL-13 was almost doubled upon OVA challenge as measured by qRT-PCR (Fig 4B). However, in the $\mathrm{KLF}^{-/-}$mice, while the basal level of IL-13 slightly increased (Fig 4C), most likely due to Th2-biased development in the mice, the OVA challenge did not increase IL-13 expression. In agreement with the sRaw data, Trichrome staining suggested increased fibrosis in the subepithelial areas upon OVA challenge in the WT mice, but there were no differences between the basal and the OVA challenged airways in $\mathrm{KLF}^{-/-}$mice (Fig 4C). In addition, CCR2+MDSCs increased from 5.9\% to $9.5 \%$ after OVA challenge in the WT mice. In the $\mathrm{KLF}^{-/}{ }^{-}$mice, basal levels of CCR2+MDSCs were increased to $12.3 \%$. However, OVA challenge did not alter the population of these cells (Fig 4D). Furthermore, consistent with the increased CCR2+MDSCs in the WT mice after OVA challenge, CD45+COL1A1+ fibrocytes also increased. Surprisingly, the elevated basal population of CCR2+MDSCs in $\mathrm{KLF}^{-/-}$mice was not associated with increased numbers of fibrocytes. Upon OVA challenge, there was no increase of CCR2+MDSCs, but the fibrocyte population decreased by more than $50 \%$ in $\mathrm{KLF}^{-1-}$ mice (Fig 4E).

\section{Discussion}

Although our data clearly showed that KLF4 is involved in airway inflammation and remodeling, the specific role of KLF4 in asthma appears to be complex. In the wild type mice, KLF4 expression is upregulated upon allergen challenge along with severity of disease (Fig 1 and 2), which may suggest that KLF4 promotes asthma. In addition, the increased infiltration of MDSCs in this setting is aligned with the role of KLF4 in recruitment of MDSCs. However, in KLF4 deficient mice, the basal level of MDSCs increased (Fig 4D), but specific airway resistance (sRaw) as measured by whole body plethysmography was decreased. This is not consistent with the role of KLF4 in promoting asthma and the role of KLF4 in MDSC recruitment. On the other hand, in KLF4 deficient mice, the asthma responses upon OVA challenge, including the sRAW, fibrotic progression, IL13 upregulation, and enrichment of MDSCs and fibrocytes are significantly disrupted (Fig 4). Together, out data support the hypothesis that KLF4 has different roles in initiation and progression of asthma at least in the allergic asthma model. Additional asthma models, including chronic asthma mouse models and allergic mouse models with different allergen challenge [32] need to be used to confirm our observations in future studies. At a cellular level, we found that in the progression of asthma upon OVA challenge, upregulated KLF4 
expression is linked with high levels of MDSCs (Fig 1) which was supported by reduced levels of MDSCs and fibrocytes in the presence of KLF4 deficiencies upon OVA challenge (Fig 4). These observations expanded upon our previous findings of KLF4 regulation of MDSC differentiation to fibrocytes in cancer [17] and cutaneous wound healing [16], which collectively suggests a universal role of KLF4-mediated MDSC plasticity in inflammationrelated human diseases. However, the specific role of MDSC-derived fibrocytes in different systems needs to be investigated further.

TSLP is important in the development of asthma and other atopic diseases, such as the chronic inflammatory skin disease atopic dermatitis (AD). TSLP overexpression in mouse skin results in a spontaneous atopic dermatitis-like disease, whereas overexpression of TSLP in the lung, results in the development of severe airway inflammation and AHR [12]. Our current data showing the association of gene expression of KLF4 and TSLP in asthma, coupled with the role of KLF4 in wound healing and skin barrier formation, suggest that transcription factor KLF4 may directly regulate TSLP in lung and skin epithelial cells in these pathological processes. The presence of potential KLF4 binding sites in the mouse TSLP promoting region further confirmed this possibility (data not shown). Additional experiments, such as a chromatin immunoprecipitation assay to examine the binding of KLF4 to the TSLP promoter, and a reporter assay to assess the regulation of TSLP promoter activities by the overexpression of KLF4, will need to be performed to test the direct regulation of TSLP by KLF4. Moreover, it will be very intriguing to examine whether TSLP could rescue KLF4 deficiency-induced abnormalities in our asthma model. If confirmed, it will suggest a significant role for KLF4/TSLP signaling in asthma and potentially in AD and other skin diseases.

In conclusion, the current study reports that KLF4 promotes airway inflammation and remodeling in an acute mouse model of asthma. In addition, our data support the hypothesis that KLF4 expression in both monocytes and epithelial cells contributes to this process through promoting the differentiation of MDSCs to fibrocytes. In the epithelial cells, TSLP likely mediates the effect of KLF4 by increasing Th2 cytokine secretion leading to fibrocyte generation. Moreover, we speculate that MDSCs regulate airway inflammation and MDSCderived fibrocytes promote airway remodeling through EMT.

\section{Supplementary Material}

Refer to Web version on PubMed Central for supplementary material.

\section{Acknowledgments}

This work was supported by SC INBRE grant (P20GM103499) to WA.

\section{References}

1. Myers TR, Tomasio L. Asthma: 2015 and beyond. Respiratory care. 2011; 56:1389-1407. discussion 1407-1310. [PubMed: 21944687]

2. Wilson DH, Adams RJ, Tucker G, Appleton S, Taylor AW, Ruffin RE. Trends in asthma prevalence and population changes in South Australia, 1990-2003. The Medical journal of Australia. 2006; 184:226-229. [PubMed: 16515433] 
3. Fahy JV. Type 2 inflammation in asthma - present in most, absent in many. Nature reviews Immunology. 2014; 15:57-65.

4. Georas SN, Rezaee F. Epithelial barrier function: at the front line of asthma immunology and allergic airway inflammation. The Journal of allergy and clinical immunology. 2014; 134:509-520. [PubMed: 25085341]

5. Manjili MH. Phenotypic plasticity of MDSC in cancers. Immunological investigations. 2012; 41:711-721. [PubMed: 23017142]

6. Arora M, Poe SL, Oriss TB, Krishnamoorthy N, Yarlagadda M, Wenzel SE, Billiar TR, Ray A, Ray P. TLR4/MyD88-induced CD11b+Gr-1 int F4/80+ non-migratory myeloid cells suppress Th2 effector function in the lung. Mucosal immunology. 2010; 3:578-593. [PubMed: 20664577]

7. Ostrand-Rosenberg S, Sinha P. Myeloid-derived suppressor cells: linking inflammation and cancer. Journal of immunology. 2009; 182:4499-4506.

8. Galligan CL, Fish EN. The role of circulating fibrocytes in inflammation and autoimmunity. Journal of leukocyte biology. 2013; 93:45-50. [PubMed: 22993208]

9. Reilkoff RA, Bucala R, Herzog EL. Fibrocytes: emerging effector cells in chronic inflammation. Nature reviews Immunology. 2011; 11:427-435.

10. Westergren-Thorsson G, Larsen K, Nihlberg K, Andersson-Sjoland A, Hallgren O, Marko-Varga G, Bjermer L. Pathological airway remodelling in inflammation. The clinical respiratory journal. 2010; 4(Suppl 1):1-8.

11. Schmidt M, Sun G, Stacey MA, Mori L, Mattoli S. Identification of circulating fibrocytes as precursors of bronchial myofibroblasts in asthma. Journal of immunology. 2003; 171:380-389.

12. Zhou B, Comeau MR, De Smedt T, Liggitt HD, Dahl ME, Lewis DB, Gyarmati D, Aye T, Campbell DJ, Ziegler SF. Thymic stromal lymphopoietin as a key initiator of allergic airway inflammation in mice. Nature immunology. 2005; 6:1047-1053. [PubMed: 16142237]

13. Gauvreau GM, O’Byrne PM, Boulet LP, Wang Y, Cockcroft D, Bigler J, FitzGerald JM, Boedigheimer M, Davis BE, Dias C, Gorski KS, Smith L, Bautista E, Comeau MR, Leigh R, Parnes JR. Effects of an anti-TSLP antibody on allergen-induced asthmatic responses. The New England journal of medicine. 2014; 370:2102-2110. [PubMed: 24846652]

14. Takai T. TSLP expression: cellular sources, triggers, and regulatory mechanisms, Allergology international. official journal of the Japanese Society of Allergology. 2012; 61:3-17.

15. Shao DD, Suresh R, Vakil V, Gomer RH, Pilling D. Pivotal Advance: Th-1 cytokines inhibit, and Th-2 cytokines promote fibrocyte differentiation. Journal of leukocyte biology. 2008; 83:13231333. [PubMed: 18332234]

16. Ou L, Shi Y, Dong W, Liu C, Schmidt TJ, Nagarkatti P, Nagarkatti M, Fan D, Ai W. Kruppel-like factor KLF4 facilitates cutaneous wound healing by promoting fibrocyte generation from myeloidderived suppressor cells. The Journal of investigative dermatology. 2015; 135:1425-1434. [PubMed: 25581502]

17. Shi Y, Ou L, Han S, Li M, Pena MM, Pena EA, Liu C, Nagarkatti M, Fan D, Ai W. Deficiency of Kruppel-like factor KLF4 in myeloid-derived suppressor cells inhibits tumor pulmonary metastasis in mice accompanied by decreased fibrocytes. Oncogenesis. 2014; 3:e129. [PubMed: 25417726]

18. Feinberg MW, Cao Z, Wara AK, Lebedeva MA, Senbanerjee S, Jain MK. Kruppel-like factor 4 is a mediator of proinflammatory signaling in macrophages. J Biol Chem. 2005; 280:38247-38258. [PubMed: 16169848]

19. Alder JK, Georgantas RW 3rd, Hildreth RL, Kaplan IM, Morisot S, Yu X, McDevitt M, Civin CI. Kruppel-like factor 4 is essential for inflammatory monocyte differentiation in vivo. Journal of immunology. 2008; 180:5645-5652.

20. Katz JP, Perreault N, Goldstein BG, Lee CS, Labosky PA, Yang VW, Kaestner KH. The zinc-finger transcription factor Klf4 is required for terminal differentiation of goblet cells in the colon. Development. 2002; 129:2619-2628. [PubMed: 12015290]

21. van den Brule S, Heymans J, Havaux X, Renauld JC, Lison D, Huaux F, Denis O. Profibrotic effect of IL-9 overexpression in a model of airway remodeling. Am J Respir Cell Mol Biol. 2007; 37:202-209. [PubMed: 17446528] 
22. Guo HW, Yun CX, Hou GH, Du J, Huang X, Lu Y, Keller ET, Zhang J, Deng JG. Mangiferin attenuates TH1/TH2 cytokine imbalance in an ovalbumin-induced asthmatic mouse model. PloS one. 2014; 9:e100394. [PubMed: 24955743]

23. Gabriele L, Schiavoni G, Mattei F, Sanchez M, Sestili P, Butteroni C, Businaro R, Mirchandani A, Niedbala W, Liew FY, Afferni C. Novel allergic asthma model demonstrates ST2-dependent dendritic cell targeting by cypress pollen. The Journal of allergy and clinical immunology. 2013; 132:686-695 e687. [PubMed: 23608732]

24. Deshane J, Zmijewski JW, Luther R, Gaggar A, Deshane R, Lai JF, Xu X, Spell M, Estell K, Weaver CT, Abraham E, Schwiebert LM, Chaplin DD. Free radical-producing myeloid-derived regulatory cells: potent activators and suppressors of lung inflammation and airway hyperresponsiveness. Mucosal immunology. 2011; 4:503-518. [PubMed: 21471960]

25. Yu F, Shi Y, Wang J, Li J, Fan D, Ai W. Deficiency of Kruppel-like factor KLF4 in mammary tumor cells inhibits tumor growth and pulmonary metastasis and is accompanied by compromised recruitment of myeloid-derived suppressor cells. International journal of cancer Journal international du cancer. 2013; 133:2872-2883. [PubMed: 23737434]

26. Quatresooz P, Hermanns-Le T, Pierard GE, Humbert P, Delvenne P, Pierard-Franchimont C. Ustekinumab in psoriasis immunopathology with emphasis on the Th17-IL23 axis: a primer. Journal of biomedicine \& biotechnology. 2012; 2012:147413. [PubMed: 22754278]

27. Ansel KM, Djuretic I, Tanasa B, Rao A. Regulation of Th2 differentiation and Il4 locus accessibility. Annual review of immunology. 2006; 24:607-656.

28. Torti DC, Feldman SR. Interleukin-12, interleukin-23, and psoriasis: current prospects. Journal of the American Academy of Dermatology. 2007; 57:1059-1068. [PubMed: 17706835]

29. Sawanobori Y, Ueha S, Kurachi M, Shimaoka T, Talmadge JE, Abe J, Shono Y, Kitabatake M, Kakimi K, Mukaida N, Matsushima K. Chemokine-mediated rapid turnover of myeloid-derived suppressor cells in tumor-bearing mice. Blood. 2008; 111:5457-5466. [PubMed: 18375791]

30. Chuluyan HE, Schall TJ, Yoshimura T, Issekutz AC. IL-1 activation of endothelium supports VLA-4 (CD49d/CD29)-mediated monocyte transendothelial migration to C5a, MIP-1 alpha, RANTES, and PAF but inhibits migration to MCP-1: a regulatory role for endothelium-derived MCP-1. Journal of leukocyte biology. 1995; 58:71-79. [PubMed: 7542307]

31. Haile LA, Gamrekelashvili J, Manns MP, Korangy F, Greten TF. CD49d is a new marker for distinct myeloid-derived suppressor cell subpopulations in mice. Journal of immunology. 2010; 185:203-210.

32. Mullane K, Williams M. Animal models of asthma: reprise or reboot? Biochem Pharmacol. 2014; 87:131-139. [PubMed: 23831953] 
- $\quad$ KLF4 in both MDSCs and lung epithelial cells controls asthma development

- $\quad$ TSLP likely mediates the effect of KLF4 in lung epithelial cells on asthma

- $\quad$ MDSC-expressing KLF4 promotes asthma in a fibrocyte-dependent manner 

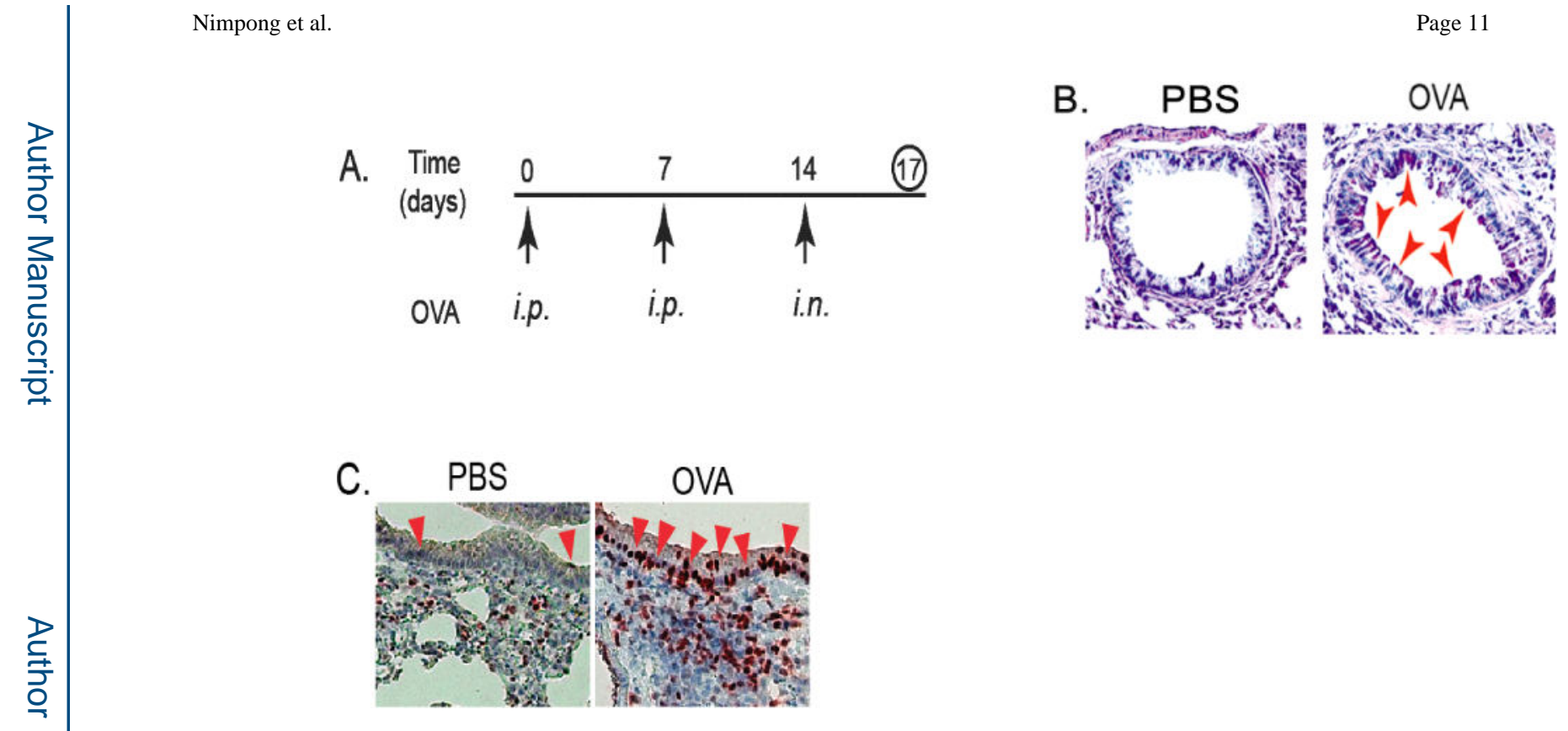

Figure 1. Increased infiltration of MDSCs was accompanied by up-regulated gene expression of KLF4 and TSLP in the lung upon asthmatic challenge

A. An accute mouse model of allergic asthma as described in the Materials and Methods. i.p. represents intraperitoneal injection and i.n. represents intranasal injection. B. Mouse lung tissues were obtained, cut and mounted on slides, and PAS (Periodic Acid Schiff) staining performed. Red arrows indicated representative stain-positive goblet cells. C. IHC staining of KLF4 from control and OVA-challenged lung tissues using KLF4 antibodies. Red arrows indicate representative KLF4-positive epithelial cells. 
A

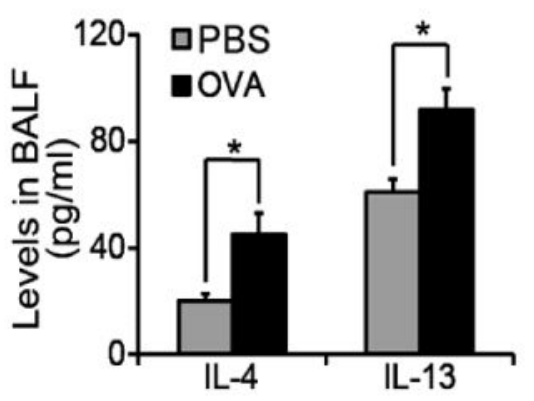

C

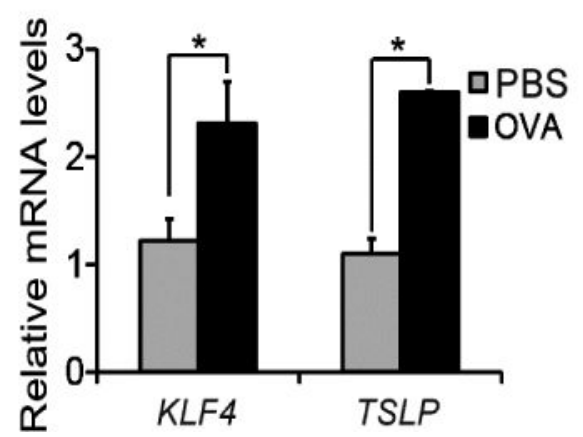

B

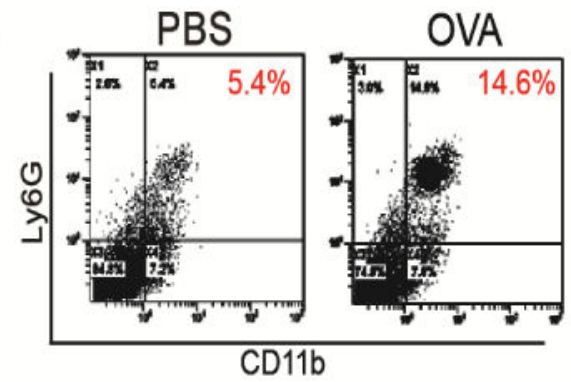

Figure 2. Increased infiltration of MDSCs was accompanied by up-regulated gene expression of KLF4 and TSLP in the lung upon asthmatic challenge

A. Mouse bronchoaveolar lavage fluids (BALF) were collected in control or OVA challenged mice, followed by cytokine measurement by ELISA. B. Single cells from lung tissues upon control or OVA challenge were purified, followed by flow cytometric analysis of MDSCs in the lung using CD11b and Ly6G antibodies. C. From the control and OVA challeged mice, total RNA from the lung tissues were extracted, cDNA were made and expression of $K L F 4$ and $F S P-1$ in the lung were analysed by quantitative RT-PCR. * $p<0.05$ between control and treatment groups, $\mathrm{n}=3$. 

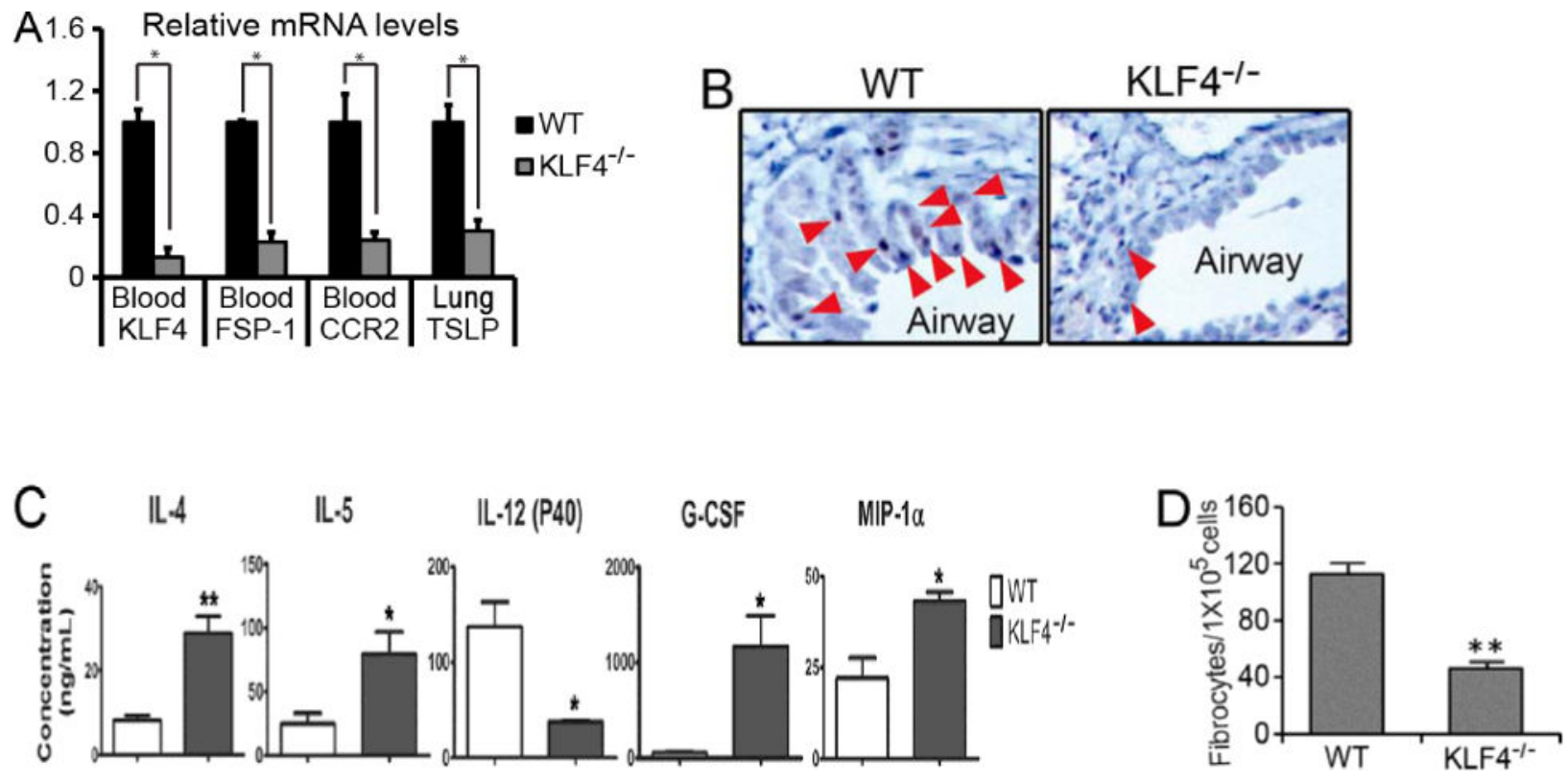

Figure 3. KLF4 ablation in CCR2+MDSCs in mice decreased TSLP expression in the lung and attenuated fibrocyte generation-establishment of FSP-1-Cre/KLF4(flox) mouse model

A. Total RNA from specific tissues as indicated were extracted and cDNA were made from the wild type (WT) and FSP-1-Cre/KLF4(flox) $\left(\mathrm{KLF}^{-1-}\right)$ mice. Gene expression of $K L F 4$, $F S P-1, C C R 2$, and TSLP were then analyzed by qRT-PCR. ${ }^{*} p<0.05$. B. KLF4 staining in the airway epithelial cells in the wild type (WT) and $\mathrm{KLF}^{-/-}$mice were examined by IHC. C. Quantification of different serum cytokines by ELISA in the WT and KLF4 ${ }^{-/-}$mice ( $\mathrm{n}=3$ in each group). ${ }^{*} p<0.05$. D. Fibrocyte generation from spleen cells of the WT and KLF4 ${ }^{-/-}$ mice were performed and the numbers of generated fibrocytes in each $10^{5}$ spleen cells were plotted $(\mathrm{n}=3) . * * p<0.01$ 

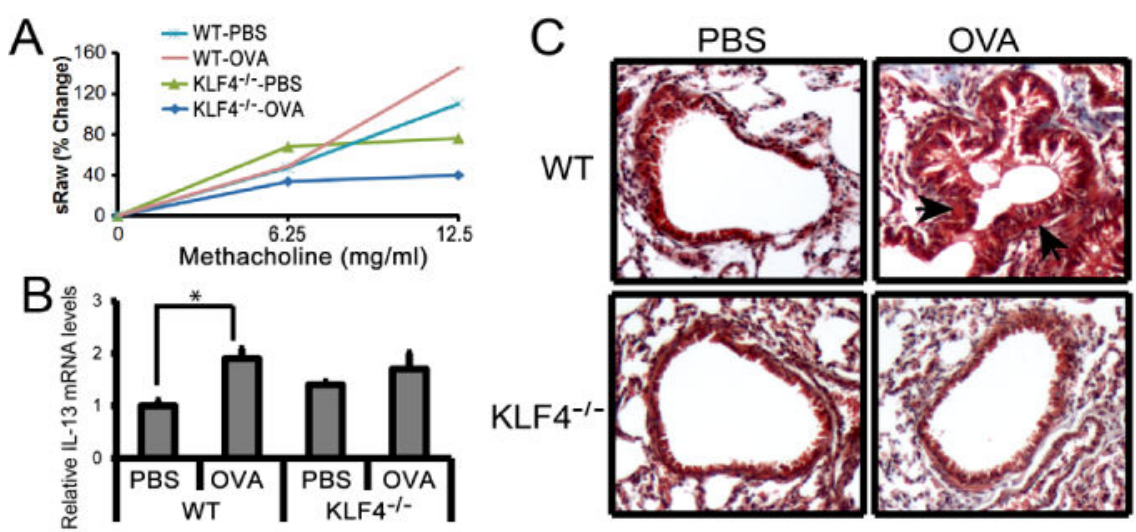

$\mathrm{KLF}^{-1-}$

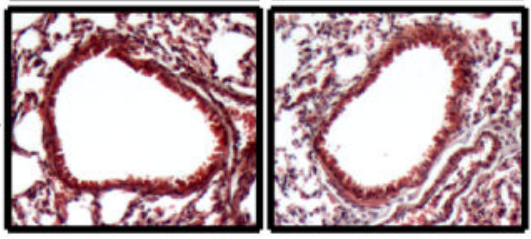

$\mathrm{D}$
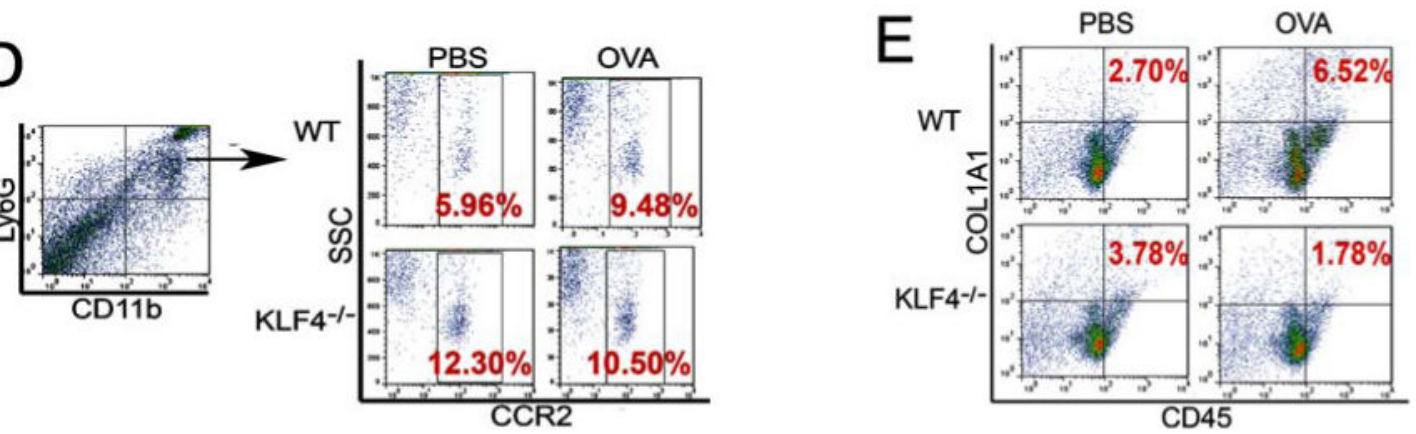

Figure 4. Attenuated AHR and fibrosis in an acute model of allergic asthma in KLF4 knockout mice, accompanied by significantly decreased numbers of fibrocytes

A. Measurement of specific airway resistance (sRaw) by non-invasive whole-body plethysmography in the WT and $\mathrm{KLF}^{-/-}$mice upon OVA challenge as described in the Materials and Methods. B. IL-13 expression levels in the lungs of the wild type (WT) and KLF4-/- mice upon control or OVA challenge were assessed by qRT-PCR. $\mathrm{n}=3,{ }^{*} p<0.05$. C. Trichrome staining to examine lung fibrosis before and after OVA challenge in WT and KLF4-/- mice. Arrows point to possible fibrotic areas. D. After gating CD11b+Ly6G+ MDSCs, populations of CCR2+MDSCs in the lungs of WT and KLF4-/- mice before and after OVA challenge were measured by flow cytometry. E. Simiar to D, CD45+COL1A1+ fibrocytes in the lungs were measured by flow cytometry. 